\title{
Impact of patient-prosthesis mismatch after transcatheter aortic valve-in-valve implantation in degenerated bioprostheses
}

\author{
Moritz Seiffert, MD, ${ }^{\mathrm{a}}$ Lenard Conradi, MD, ${ }^{\mathrm{a}}$ Stephan Baldus, MD, ${ }^{\mathrm{b}}$ Malgorzata Knap, MD, \\ Johannes Schirmer, MD, ${ }^{\mathrm{a}}$ Olaf Franzen, MD, ${ }^{\mathrm{b}}$ Dietmar Koschyk, MD, ${ }^{\mathrm{b}}$ Thomas Meinertz, MD, ${ }^{\mathrm{b}}$ \\ Hermann Reichenspurner, $\mathrm{MD}, \mathrm{PhD},{ }^{\mathrm{a}}$ and Hendrik Treede, $\mathrm{MD}^{\mathrm{a}}$
}

\begin{abstract}
Objective: Transcatheter valve-in-valve implantation is evolving as an alternative to reoperative valve replacement in high-risk patients with degenerated bioprostheses. Nevertheless, hemodynamic performance is limited by the previously implanted xenograft. We report our experience with patient-prosthesis mismatch (PPM) after valve-in-valve implantation in the aortic position.
\end{abstract}

\begin{abstract}
Methods: Eleven patients (aged $79.3 \pm 6.1$ years) received transapical implantation of a balloon-expandable pericardial heart valve into a degenerated bioprosthesis (size, $23.9 \pm 1.6 \mathrm{~mm}$; range, $21-27 \mathrm{~mm}$ ) in the aortic position. All patients were considered high risk for surgical valve replacement (logistic European System for Cardiac Operative Risk Evaluation, 31.8\% $\pm 24.1 \%$ ). Severe PPM was defined as an indexed effective orifice area less than $0.65 \mathrm{~cm}^{2} / \mathrm{m}^{2}$, determined by discharge echocardiography.
\end{abstract}

\begin{abstract}
Results: Severe PPM was evident in 5 patients (group 1) and absent in 6 patients (group 2). Mean transvalvular gradients decreased from $29.2 \pm 15.4 \mathrm{~mm} \mathrm{Hg}$ before implantation to $21.2 \pm 9.7 \mathrm{~mm} \mathrm{Hg}$ at discharge (group 1) and from $28.2 \pm 9.0 \mathrm{~mm} \mathrm{Hg}$ before implantation to $15.2 \pm 6.5 \mathrm{~mm} \mathrm{Hg}$ at discharge (group 2). Indexed effective orifice area increased from $0.5 \pm 0.1 \mathrm{~cm}^{2} / \mathrm{m}^{2}$ to $0.6 \pm 0.1 \mathrm{~cm}^{2} / \mathrm{m}^{2}$ and from $0.6 \pm 0.3 \mathrm{~cm}^{2} / \mathrm{m}^{2}$ to $0.8 \pm 0.3 \mathrm{~cm}^{2} /$ $\mathrm{m}^{2}$. Aortic regurgitation decreased from grade $2.0 \pm 1.1$ to $0.4 \pm 0.5$ overall. No differences in New York Heart Association class improvement or survival during follow-up were observed. One patient required reoperation for symptomatic PPM 426 days after implantation.
\end{abstract}

Conclusions: Valve-in-valve implantation can be performed in high-risk surgical patients to avoid reoperation. However, PPM frequently occurs, making adequate patient selection crucial. Small bioprostheses $(<23 \mathrm{~mm})$ should be avoided. Implantation into 23-mm xenografts can be recommended only for patients with a body surface area less than $1.8 \mathrm{~m}^{2}$. Larger prostheses seem to carry a lower risk for PPM. Although no delay in clinical improvement was seen at short-term, 1 PPM-related surgical intervention raises concern regarding long-term performance. (J Thorac Cardiovasc Surg 2012;143:617-24)

Transcatheter valve therapies have been evolving as promising alternatives to conventional surgery in high-risk patients. Transcatheter valve-in-valve implantation can spare elderly patients reoperative valve replacement for degenerated bioprostheses. First experiences with this novel approach have been published and seem appealing in the light of the high risk associated with conventional redo surgery in these frail patients. ${ }^{1-4}$ At the same time, concerns have been raised regarding valve-in-valve function and

\footnotetext{
From the Departments of Cardiovascular Surgery ${ }^{\mathrm{a}}$ and General and Interventional Cardiology, ${ }^{\mathrm{b}}$ University Heart Center Hamburg, Germany.

Disclosures: Dr Franzen received lecture fees from Edwards Lifesciences. All other authors have nothing to disclose with regard to commercial support.

M.S. and L.C. contributed equally to this work.

Read at the 91st Annual Meeting of The American Association for Thoracic Surgery, Philadelphia, Pennsylvania, May 7-11, 2011.

Received for publication May 7, 2011; revisions received July 15, 2011; accepted for publication Nov 7, 2011; available ahead of print Dec 12, 2011.

Address for reprints: Moritz Seiffert, MD, Department of Cardiovascular Surgery, University Heart Center Hamburg, Martinistrasse 52, 20246 Hamburg, Germany (E-mail: m.seiffert@uke.de).

$0022-5223 / \$ 36.00$

Copyright (c) 2012 by The American Association for Thoracic Surgery doi:10.1016/j.jtcvs.2011.11.004
}

the suitability of a variety of market-approved bioprostheses for the accommodation of 2 or 3 sizes of transcatheter heart valves (THVs) not specifically designed for valvein-valve implantation. Hemodynamic performance of the valve-in-valve construct inevitably is limited by annular geometry defined through the previously implanted xenograft and its rigid stent.

Several cases of residual stenoses, increased transvalvular gradients, and low effective orifice areas (EOAs) have been described after valve-in-valve procedures, ${ }^{5}$ making patient-prosthesis mismatch (PPM) a concern. ${ }^{6}$ PPM has been extensively investigated as a potential problem after surgical valve replacement and is considered as an EOA of the valve prosthesis that is physiologically too small in relation to the patient's body surface area (BSA). ${ }^{7}$ The rationale is that a smaller EOA will result in higher transvalvular gradients. The indexed EOA (iEOA) is the only parameter found to consistently correlate with postoperative gradients. PPM is generally defined as iEOA $0.85 \mathrm{~cm}^{2} / \mathrm{m}^{2}$ or less (moderate) or iEOA $0.65 \mathrm{~cm}^{2} / \mathrm{m}^{2}$ or less (severe). ${ }^{8} \mathrm{Al}$ though there has been much controversy regarding the influence of moderate PPM, there has been considerable 


\section{Abbreviations and Acronyms \\ $\mathrm{AR}=$ aortic regurgitation \\ AVR = aortic valve replacement \\ BSA = body surface area \\ EOA $=$ effective orifice area \\ iEOA $=$ indexed effective orifice area \\ NYHA $=$ New York Heart Association \\ PPM = patient-prosthesis mismatch \\ $\mathrm{THV}=$ transcatheter heart valve}

evidence that severe PPM has a negative impact on patient outcome. ${ }^{9}$

By implanting 1 valve within another instead of replacing it and the lack of oversizing, valve-in-valve procedures seem predestined for the occurrence of PPM. This problem has been investigated in vitro. Although implantation of a 23-mm THV into a stented 23-mm bioprosthesis reduced transprosthetic pressure gradients and improved EOA similar to surgical aortic valve replacement (AVR), implantation into smaller valves insufficiently relieved the stenosis. ${ }^{10}$ Furthermore, the rigidity of the bioprosthesis stent can constrain oversized valve-in-valve implantation and prevent full expansion, leading to leaflet distortion and subsequent transvalvular aortic regurgitation (AR).

Systematic investigation of PPM after valve-in-valve implantation has not been performed. The current study retrospectively analyzed the data of valve-in-valve implantations performed at University Heart Center Hamburg to address this issue and attempts to offer guidance to prevent this potential problem.

\section{MATERIALS AND METHODS \\ Patient Population}

From August 2008 to March 2011, 11 patients were admitted to the University Heart Center Hamburg with significant signs of valve dysfunction (stenosis, regurgitation, mixed disease) long-term after bioprosthetic AVR. Indication for valve replacement was based on current guidelines. ${ }^{11}$ All patients presented with severe comorbidities precluding them from surgical treatment as determined by an interdisciplinary heart team. Preoperative transesophageal echocardiography was used to determine valve pathology and inner stent diameter; computed tomography scans of the aortic arch and femoral vessels were used to assess vascular status. The transapical approach was chosen for the straight and short access to the site of valve implantation in all patients.

\section{Transcatheter Valve-in-Valve Implantation}

Transcatheter valve-in-valve implantation was performed in a specially equipped hybrid suite under general anesthesia, as previously described. ${ }^{3}$ Briefly, after left lateral minithoracotomy and ventricular pacemaker-lead placement, pursestring sutures were applied and a transapical guidewire was inserted. Subsequently, the crimped Edwards SAPIEN THV (Edwards Lifesciences LLC, Irving, Calif) was introduced through a sheath and deployed into the degenerated xenograft prosthesis antegrade in the aortic position without prior balloon valvuloplasty of the degenerated prosthesis.
These steps were carried out under rapid ventricular pacing and fluoroscopic control. Subsequently, valve performance was assessed by transesophageal echocardiography and fluoroscopy. A 23-mm balloon-expandable valve was used in 10 patients, and a $26-\mathrm{mm}$ device was used in 1 patient.

\section{Echocardiographic Assessment and Follow-up}

Transthoracic echocardiography was performed at baseline and before discharge. ${ }^{12}$ The EOA was assessed using the continuity equation approach. The iEOA was calculated by dividing the EOA with the patient's BSA, computed using the Dubois formula (BSA $\left[\mathrm{m}^{2}\right]=0.007184 \cdot$ weight $[\mathrm{kg}]^{0.425} \cdot$ height $[\mathrm{cm}]^{0.725}$ ). According to the literature, severe PPM was defined as iEOA $0.65 \mathrm{~cm}^{2} / \mathrm{m}^{2}$ or less. ${ }^{8}$ Patients with severe PPM after valve-in-valve implantation were included in group 1. Patients without echocardiographic evidence of severe mismatch were included in group 2. Follow-up was performed at 30 days, 6 months, and 1 year, if applicable, collecting data regarding functional status (New York Heart Association [NYHA] class), echocardiographic valve function, and mortality.

\section{Statistical Methods}

Continuous variables are expressed as mean \pm standard deviation, and categoric variables are expressed as proportions (\%). The mean values of continuous variables were compared using the Student $t$ test generating 2 -tailed $P$ values. Categoric variables were compared using the Fisher exact test. Cumulative probability of survival was estimated using the KaplanMeier method and compared between groups using the log-rank test. All statistical analyses were performed using GraphPad Prism version 5.02 (GraphPad Software, Inc, La Jolla, Calif).

\section{RESULTS}

The study population was predominantly male with a mean age of $79.1 \pm 6.3$ years (range, $70-88$ years; Table 1). Patients were admitted with severe degeneration of the implanted bioprostheses $12.6 \pm 6.2$ years after surgical AVR. Ten patients had stented bioprostheses sizes 21 to $25 \mathrm{~mm}$ in situ, and 1 patient had a stentless $27-\mathrm{mm}$ valve (Table 2). Overall, 4 patients $(36 \%)$ primarily displayed signs of stenosis of the previously implanted xenograft, and 4 patients $(36 \%)$ presented with regurgitation, mostly due to prolapse of a single cusp. Three patients (27\%) showed a mixed disease. Baseline characteristics including echocardiographic measurements and comorbidities are presented in Table 1. After transcatheter aortic valve-invalve implantation, 5 patients had an iEOA $0.65 \mathrm{~cm}^{2} / \mathrm{m}^{2}$ or less (severe PPM, group 1), 5 patients had an iEOA less than $0.85 \mathrm{~cm}^{2} / \mathrm{m}^{2}$ but greater than $0.65 \mathrm{~cm}^{2} / \mathrm{m}^{2}$ (moderate PPM, group 2), and 1 patient had an iEOA greater than $0.85 \mathrm{~cm}^{2} / \mathrm{m}^{2}$ (no PPM, group 2), as determined by echocardiography at discharge. No statistically significant differences in baseline parameters were observed between both groups, although there was a trend toward a higher risk profile in group 1.

In both groups, the iEOA improved only slightly after valve-in-valve implantation, missing statistical significance (group 1, $0.50 \pm 0.13$ to $0.58 \pm 0.06 \mathrm{~cm}^{2} / \mathrm{m}^{2}$; group 2, 0.62 \pm 0.27 to $0.83 \pm 0.28 \mathrm{~cm}^{2} / \mathrm{m}^{2}$; Figure $1, A$ ). A significant reduction in mean aortic valve gradient from $28.2 \pm 9.0$ $\mathrm{mm} \mathrm{Hg}$ at baseline to $15.2 \pm 6.5 \mathrm{~mm} \mathrm{Hg}$ at discharge was observed in group $2(P=.02)$, whereas only a mild decrease 
TABLE 1. Baseline and clinical parameters, mean \pm standard deviation

\begin{tabular}{|c|c|c|c|}
\hline & Group $1\left(\right.$ iEOA $\left.\leq 0.65 \mathrm{~cm}^{2} / \mathrm{m}^{2}\right)$ & Group $2\left(\right.$ iEOA $\left.>0.65 \mathrm{~cm}^{2} / \mathrm{m}^{2}\right)$ & $P$ value \\
\hline $\mathrm{n}$ & 5 & 6 & \\
\hline Age (y) & $75.5 \pm 5.6$ & $82.2 \pm 5.4$ & .07 \\
\hline Sex (male) & $5 / 5(100 \%)$ & $4 / 6(67 \%)$ & .45 \\
\hline BMI $\left(\mathrm{kg} / \mathrm{m}^{2}\right)$ & $26.7 \pm 5.5$ & $23.3 \pm 2.2$ & .20 \\
\hline $\operatorname{BSA}\left(\mathrm{m}^{2}\right)$ & $2.0 \pm 0.3$ & $1.8 \pm 0.2$ & .22 \\
\hline \multicolumn{4}{|l|}{ Preoperative diagnosis } \\
\hline AS & $2 / 5(40 \%)$ & $2 / 6(33 \%)$ & 1.0 \\
\hline $\mathrm{AR}$ & $1 / 5(20 \%)$ & $3 / 6(50 \%)$ & .54 \\
\hline Mixed disease & $2 / 5(40 \%)$ & $1 / 6(17 \%)$ & .39 \\
\hline Preoperative AVG mean $(\mathrm{mm} \mathrm{Hg})$ & $29.2 \pm 15.4$ & $28.2 \pm 9.0$ & .90 \\
\hline Preoperative iEOA $\left(\mathrm{cm}^{2} / \mathrm{m}^{2}\right)$ & $0.5 \pm 0.1$ & $0.6 \pm 0.3$ & .39 \\
\hline Preoperative AR (grade) & $2.0 \pm 1.1$ & $2.0 \pm 1.3$ & 1.0 \\
\hline Interval to index procedure $(\mathrm{y})$ & $12.4 \pm 8.0$ & $12.8 \pm 5.1$ & .92 \\
\hline Size bioprosthesis (mm) & $23.8 \pm 2.3$ & $24.0 \pm 1.1$ & .85 \\
\hline Inner stent diameter (mm) & $21.0 \pm 1.9$ & $20.2 \pm 1.1$ & .40 \\
\hline Size implanted THV (mm) & $23.6 \pm 1.3$ & $23.0 \pm 0.0$ & \\
\hline Coronary artery disease & $2 / 5(40 \%)$ & $3 / 6(50 \%)$ & 1.0 \\
\hline Previous CABG & $1 / 5(20 \%)$ & $2 / 6(33 \%)$ & 1.0 \\
\hline Extracardiac arteriopathy & $3 / 5(60 \%)$ & $1 / 6(17 \%)$ & .24 \\
\hline Preoperative creatinine $(\mathrm{mg} / \mathrm{dL})$ & $2.4 \pm 2.5$ (range, $0.6-8.9)$ & $1.1 \pm 0.3$ (range, $0.6-1.4)$ & .23 \\
\hline Severe pulmonary disease & $4 / 5(80 \%)$ & $2 / 6(33 \%)$ & .24 \\
\hline Malignant disease & $1 / 5(20 \%)$ & $0 / 6(0 \%)$ & .45 \\
\hline Preoperative LVEF (\%) & $47.0 \pm 23.1$ & $52.5 \pm 10.4$ & .61 \\
\hline Preoperative NYHA class & $3.2 \pm 0.4$ & $3.0 \pm 0.7$ & .60 \\
\hline Logistic euroSCORE (\%) & $42.0 \pm 32.9$ & $23.3 \pm 10.0$ & .21 \\
\hline STS PROM $(\%)$ & $17.8 \pm 14.6$ & $8.0 \pm 7.0$ & .18 \\
\hline
\end{tabular}

Statistical analysis was performed using the Student $t$ test for continuous and Fisher exact test for categoric variables. Inner stent diameter was measured by transesophageal echocardiography. $i E O A$, Indexed effective orifice area; $B M I$, body mass index; $B S A$, body surface area; $A S$, aortic stenosis; $A R$, aortic regurgitation; $A V G$, aortic valve gradient; $T H V$, transcatheter heart valve; $C A B G$, coronary artery bypass grafting; $L V E F$, left ventricular ejection fraction; NYHA, New York Heart Association; euroSCORE, European System for Cardiac Operative Risk Evaluation; STS PROM, Society of Thoracic Surgeons Predicted Risk of Mortality.

from $29.2 \pm 15.4 \mathrm{~mm} \mathrm{Hg}$ at baseline to $21.2 \pm 9.7 \mathrm{~mm} \mathrm{Hg}$ at discharge was detected in group $1(P=$ not significant). At later follow-up visits, no significant differences were found in either group compared with baseline (Figure 1, B).

AR was reduced from grade $2.0 \pm 1.3$ to $0.3 \pm 0.5$ $(P=.04)$ in group 2 and from grade $2.0 \pm 1.1$ at baseline to $0.4 \pm 0.5$ at discharge in group $1(P=.06)$. After valvein-valve implantation, AR was trace in all but 1 patient who had a grade 2 paravalvular AR at 6-month follow-up that was not considered to be clinically relevant at this point (Figure 1,C). No significant changes in left ventricular ejection fraction were noted in either group (Figure 1,D).

NYHA class improved from $3.2 \pm 0.4$ before the procedure to $1.7 \pm 0.5$ at 30 -day follow-up in group $1(P=.01)$ and from $3.0 \pm 0.71$ to $2.2 \pm 0.45$ in group $2(P=.03)$. At 6-month follow-up, no significant improvement was seen from baseline in either group (group 1, NYHA class 2.5 \pm 1.3 ; group 2 , NYHA class $2.0 \pm 0.8$; Figure $2, A$ ).

TABLE 2. Parameters of implanted bioprostheses and transcatheter heart valves

\begin{tabular}{lclc}
\hline Patient no. & Bioprosthesis size & \multicolumn{1}{c}{ Bioprosthesis type $^{\text {THV size }}$} \\
\hline 1 & $21 \mathrm{~mm}$ & Medtronic Hancock (Medtronic Inc, Minneapolis, Minn) & $23 \mathrm{~mm}$ \\
2 & $23 \mathrm{~mm}$ & Carpentier Edwards (Edwards Lifesciences LLC, Irvine, Calif) & $23 \mathrm{~mm}$ \\
3 & $23 \mathrm{~mm}$ & Medtronic Hancock & $23 \mathrm{~mm}$ \\
4 & $23 \mathrm{~mm}$ & Medtronic Hancock & $23 \mathrm{~mm}$ \\
5 & $23 \mathrm{~mm}$ & Medtronic Hancock & $23 \mathrm{~mm}$ \\
6 & $23 \mathrm{~mm}$ & St Jude Biocor (St Jude Medical, St Paul, Minn) & $23 \mathrm{~mm}$ \\
7 & $25 \mathrm{~mm}$ & Medtronic Hancock & $23 \mathrm{~mm}$ \\
8 & $25 \mathrm{~mm}$ & Medtronic Hancock & $23 \mathrm{~mm}$ \\
9 & $25 \mathrm{~mm}$ & Medtronic Mosaic (Medtronic Inc) & $23 \mathrm{~mm}$ \\
10 & $25 \mathrm{~mm}$ & St Jude Biocor & $23 \mathrm{~mm}$ \\
11 & $27 \mathrm{~mm}$ & Medtronic Freestyle (Medtronic Inc) & $26 \mathrm{~mm}$ \\
\hline
\end{tabular}

$T H V$, Transcatheter heart valve. 

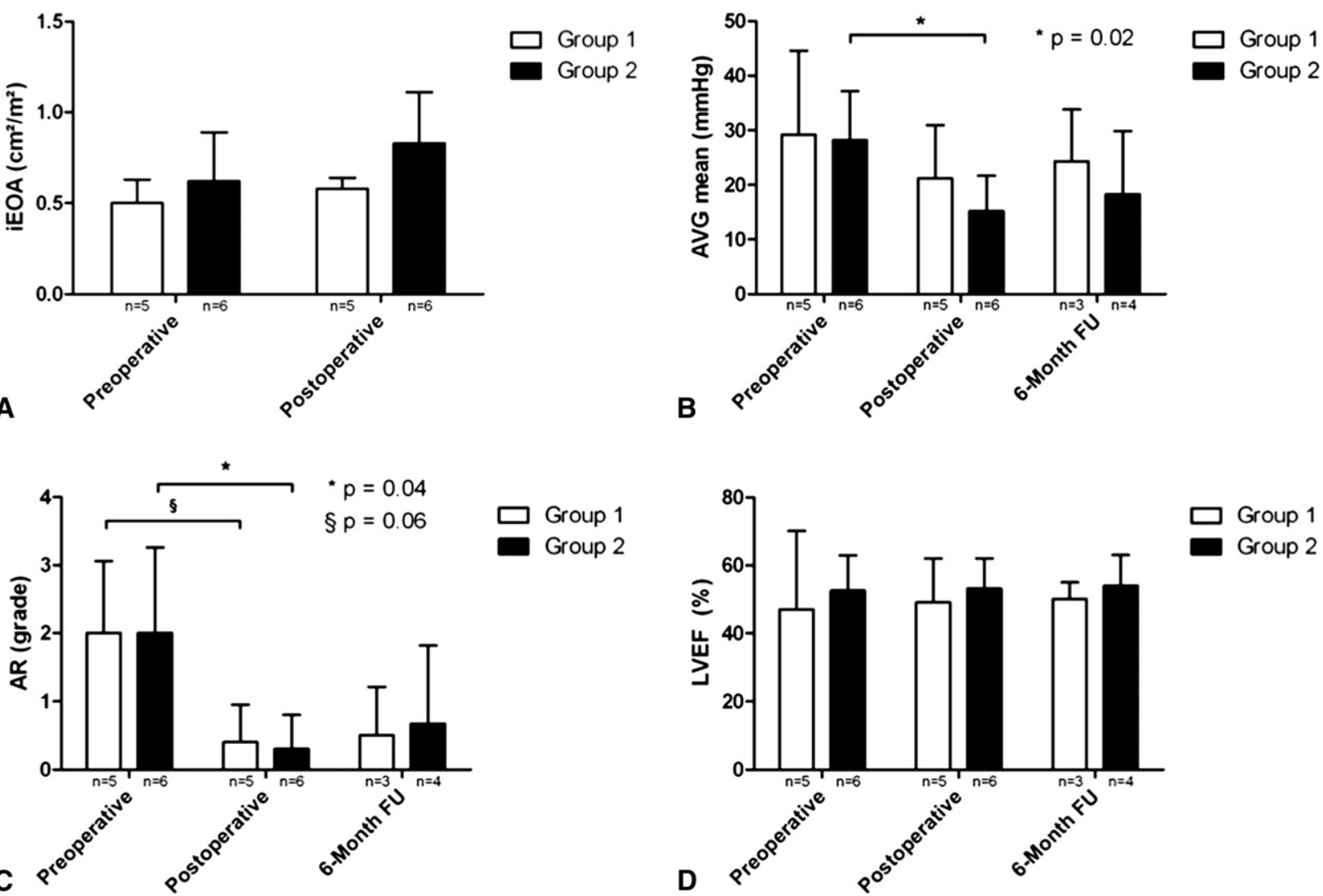

FIGURE 1. A, iEOA before and after transcatheter valve-in-valve implantation did not improve significantly in either group. B, Mean AVG decreased significantly after valve-in-valve implantation only in patients without severe PPM, but this effect was lost over a 6-month follow-up. Reduction in AR after implantation was significant only for patients in group 2. C, At 6-month follow-up, no significant effect was detectable. D, No changes in left ventricular ejection fraction were observed during follow-up in either group. Mean \pm standard deviation. Statistical analysis was performed using the paired Student $t$ test. $A V G$, Aortic valve gradient; $i E O A$, indexed effective orifice area; $A R$, aortic regurgitation; $F U$, follow-up; $L V E F$, left ventricular ejection fraction.

In group 1, 1 patient died of low cardiac output on day 8 and 1 patient died of a metastasizing prostate carcinoma 246 days after the procedure. One patient required surgical AVR and root remodeling for symptomatic stenosis (iEOA, 0.4 $\left.\mathrm{cm}^{2} / \mathrm{m}^{2}\right) 426$ days after valve-in-valve implantation into a 21-mm bioprosthesis. He was in good clinical condition at the latest follow-up. In group 2, 1 patient died of sudden cardiac failure at the rehabilitation clinic on day 33. By
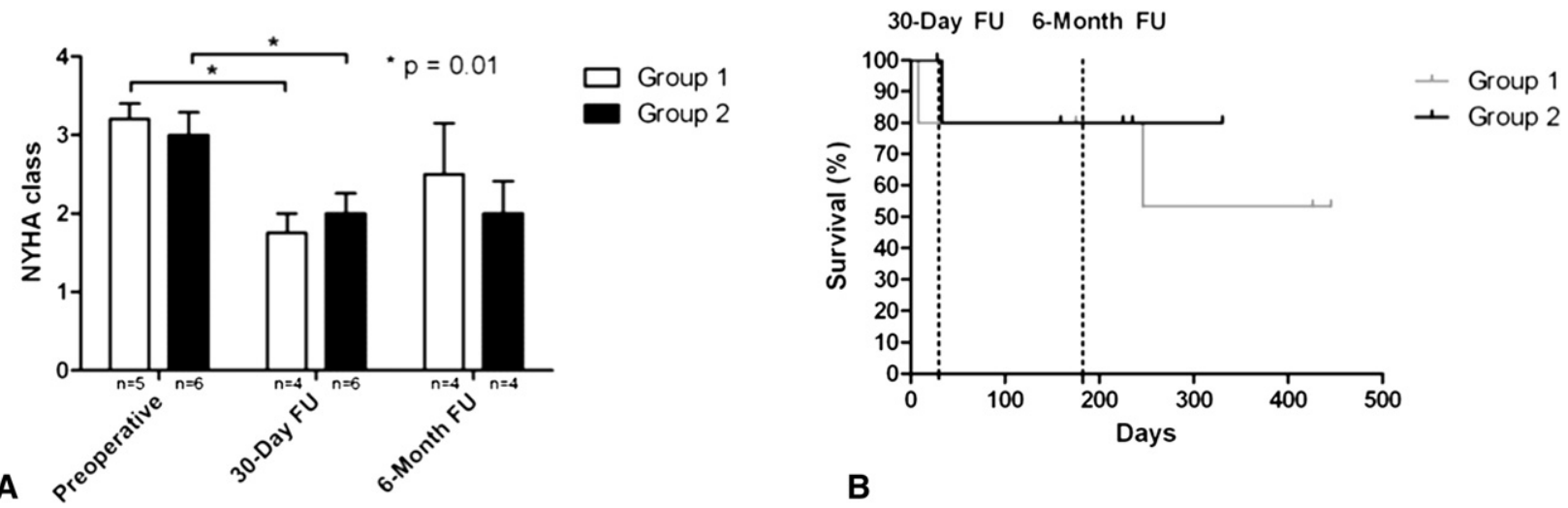

B

FIGURE 2. A, NYHA class improved significantly at 30-day follow-up in both study groups, but no statistically significant difference was noted at 6-month follow-up. Cumulative survival was estimated using the Kaplan-Meier method. Log-rank test did not detect any differences in survival between both groups $(P=.67)$. B, One patient required surgical AVR 426 days after implantation and was censored alive at that date. FU, Follow-up; NYHA, New York Heart Association. 
using the Kaplan-Meier analysis and log-rank test, no differences in survival between both groups were observed $(P=.67$; Figure $2, B)$.

\section{DISCUSSION}

Valve-in-valve implantation can be performed to avoid reoperative valve replacement in frail and elderly patients who are no candidates for conventional surgery. The small number of patients constitutes a major limitation of the presented study. Several groups have published encouraging outcomes after valve-in-valve procedures. ${ }^{1,4}$ The results were rather satisfactory in our experience. This corresponds to the fact that approximately half of the study patients had signs of severe PPM, as measured by postoperative echocardiography. All but 1 patient had at least moderate PPM (Figure 3, $A$ and $B$ ). To analyze an effect of PPM on postoperative outcome, we focused on patients with severe PPM and compared them with the remainder of patients.

In line with the literature on this topic, improvement in valve function in patients with severe PPM was ambivalent: Transvalvular gradients were significantly reduced only in patients without severe PPM underlining the correlation of iEOA and aortic valve gradient (Figure $3, A$ ). The significance to this effect was lost over follow-up, probably because of the small number of patients. Because at least moderate PPM was present in the majority of patients, no significant increase in iEOA was observed in either group. Subsequently, a persistent relative aortic stenosis might preclude an adequate left ventricular afterload relief in patients with severe PPM impeding left ventricular mass regression. Echocardiographic measurements of wall thickness and ventricular dimensions were not concise enough in this study to relate changes in left ventricular volume and hypertrophy to PPM. Nevertheless, in our experience, implantation of a THV into a 21-mm bioprosthesis did not sufficiently relieve stenosis, resulting in reoperation in that patient. Consequently, we prefer to avoid the described procedure in patients with previously implanted bioprostheses less than $23 \mathrm{~mm}$. In our experience, implantation of a THV into $23-\mathrm{mm}$ xenografts can be recommended only for patients with a BSA less than $1.8 \mathrm{~m}^{2}$ to achieve a sufficient iEOA, relieve stenosis, and avoid severe PPM. Larger prostheses seem to carry a lower risk for PPM unless BSA increases to the same extent (Figure 3, $A$ and $B$ ). This is in line with in vitro data published by Azadani and coworkers ${ }^{10}$ and our own experience. ${ }^{3}$ We found that implantation of a 23-mm THV into a 25-mm xenograft achieves a geometric EOA of $2.4 \mathrm{~cm}^{2}$, whereas implantation into a $21-\mathrm{mm}$ stented bioprosthesis offers only $1.4 \mathrm{~cm}^{2}$ at maximum (Figure 4). Of note, the geometric EOA significantly overestimates the actual in vivo EOA.

A clinically relevant reduction of AR was achieved in all patients. Valve-in-valve implantation may therefore be superior in the treatment of regurgitation rather than stenosis due to bioprosthetic degeneration. Because only 2 patients had trace paravalvular and 2 other patients displayed trace transvalvular AR after valve-in-valve implantation, relevant constraint of the THV due to the rigid bioprosthesis stent and subsequent leaflet distortion seem to be minor problems. Nevertheless, the fact that 1 patient had an increasing paravalvular AR (grade 2 at 6-month follow-up) emphasizes that alignment of bioprosthesis and THV can be hindered by uneven stent expansion and calcifications distorting the circular geometry. Development of specific THV containing a cuff for optimal alignment and reduction of paravalvular AR is under way and might solve this problem. However, cuffed THV might carry a wider stent that further decreases the resulting EOA.

Both study groups showed a mildly reduced mean left ventricular ejection fraction at baseline. No significant improvement was observed during follow-up in either group, perhaps because of persistent relative stenosis and a short follow-up time. From a clinical perspective, NYHA class improvement was seen within early follow-up in patients
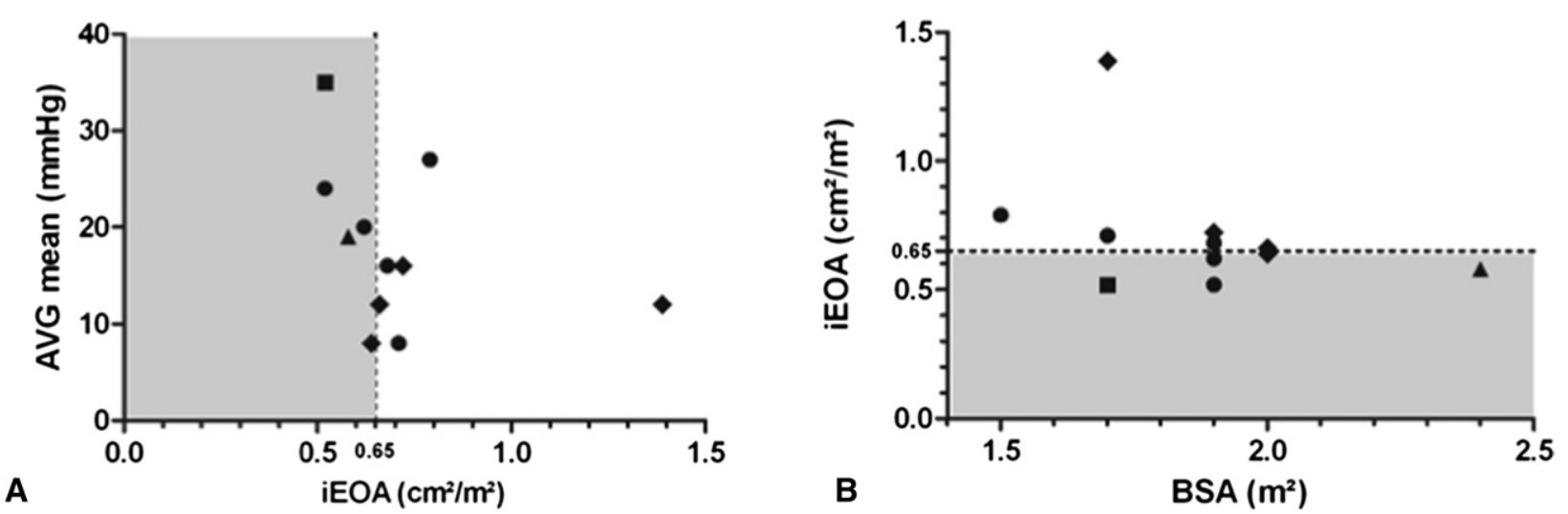

FIGURE 3. A, Relationship of mean AVG and iEOA at discharge. B, Relation of iEOA and BSA at discharge. One patient with body mass index of $34.0 \mathrm{~kg} / \mathrm{m}^{2}$ and BSA of $2.4 \mathrm{~m}^{2}$ had severe PPM despite valve-in-valve implantation into a $27-\mathrm{mm}$ stentless prosthesis. Area of PPM (grey). Sizes of previously implanted bioprostheses: $\mathbf{\square}, 21 \mathrm{~mm} ; \bullet, 23 \mathrm{~mm} ;, 25 \mathrm{~mm} ; \boldsymbol{\Lambda}, 27 \mathrm{~mm}$. AVG, Aortic valve gradient; iEOA, indexed effective orifice area; BSA, body surface area. 


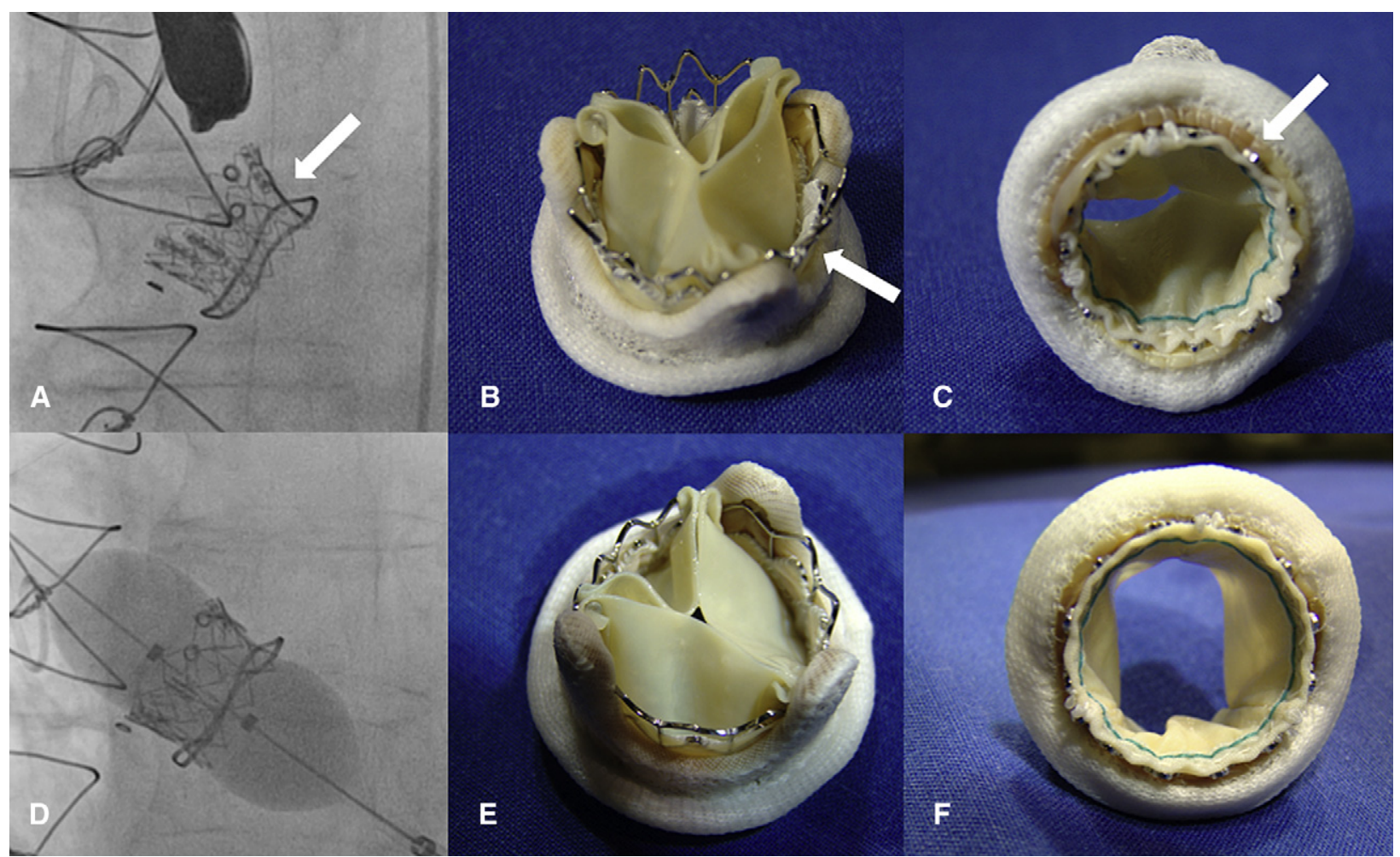

FIGURE 4. Transcatheter valve-in-valve implantation of a 23-mm Edwards SAPIEN (Edwards Lifesciences LLC, Irving, Calif) valve into a 23-mm bioprosthesis (A) and 21-mm stented bioprosthesis (B, C). Uneven stent expansion (arrows). Implantation into a 25-mm stented bioprosthesis confirms superior stent expansion and alignment within the larger bioprosthesis (D-F). Positioning of the THV with the lower third overlapping the sewing ring of the surgical prosthesis for optimal anchoring, valve expansion, and reduction of atrioventricular conduction disturbances (A, D). B, C, E, and F are modified with permission from John Wiley \& Sons, Inc. ${ }^{3}$

with and without severe PPM. Nevertheless, 1 patient had profound symptoms of heart failure in conjunction with severe PPM. He required surgical reoperation including aortic root enlargement more than 1 year after implantation, emphasizing the potential problems adherent with PPM. With regard to survival, no differences were seen between the 2 groups.

Much effort has been made to investigate the nature of PPM in patients receiving surgical AVR. Approximately $2 \%$ to $11 \%$ of these patients have severe PPM, and $20 \%$ to $70 \%$ have moderate PPM. ${ }^{9}$ After TAVI, an incidence of severe PPM of up to $16 \%$ has been reported. ${ }^{13}$ Although the influence of PPM on short- and long-term survivals is still controversial, in part because of methodical discrepancies, there is considerable evidence that severe PPM has a detrimental effect on patient outcome. ${ }^{8,13-19}$ In contrast with most other cardiovascular risk factors, PPM can largely be prevented and should therefore be avoided. For TAVI and valve-in-valve procedures, where additional surgical procedures (eg, aortic root enlargement) are not available, it is crucial to carefully select the patients and THV type and size. A major concern is the size and type of the previously implanted bioprosthesis. This issue might become secondary once smaller THV sizes and specific valve-in-valve THV become available. Another interesting approach is the supravalvular implantation of a specifically designed THV into the xenograft, potentially offering a larger EOA. ${ }^{20}$

An important aspect that has to be addressed in a largerscale study is the question of which bioprostheses are especially capable of accommodating a THV with sufficient alignment of the valve-in-valve construct offering adequate valve function. Furthermore, hemodynamic properties of different THV types in valve-in-valve position should be compared. The balloon-expandable Edwards SAPIEN valve with its low frame height and precise placement seems to be an ideal candidate for valve-in-valve implantation. However, the long frame design of the CoreValve device (Medtronic Inc, Minneapolis, Minn) may allow a supra-annular placement of the prosthesis, resulting in an increased EOA and superior hemodynamic function, especially in small bioprostheses.

\section{CONCLUSIONS}

PPM frequently occurs and has to be considered when planning valve-in-valve procedures. In this study, no delay in clinical improvement was seen in patients with severe PPM at short-term. Apart from short follow-up duration, 
this might also be attributed to a lack of physical exertion and maximum cardiovascular effort to detect differences in these elderly and frail patients. Objective functional measurements of cardiovascular capacity may have offered deeper insights. However, 1 PPM-related surgical intervention raises concerns about a potential problem that needs to be considered when planning a valve-in-valve implantation.

\section{References}

1. Webb JG, Wood DA, Ye J, Gurvitch R, Masson JB, Rodes-Cabau J, et al. Transcatheter valve-in-valve implantation for failed bioprosthetic heart valves. $\mathrm{Circu}$ lation. 2010;121:1848-57.

2. Walther T, Falk V, Dewey T, Kempfert J, Emrich F, Pfannmuller B, et al. Valvein-a-valve concept for transcatheter minimally invasive repeat xenograft implantation. J Am Coll Cardiol. 2007;50:56-60.

3. Seiffert M, Franzen O, Conradi L, Baldus S, Schirmer J, Meinertz T, et al. Series of transcatheter valve-in-valve implantations in high-risk patients with degenerated bioprostheses in aortic and mitral position. Catheter Cardiovasc Interv. 2010;76:608-15.

4. Kempfert J, Van Linden A, Linke A, Borger MA, Rastan A, Mukherjee C, et al. Transapical off-pump valve-in-valve implantation in patients with degenerated aortic xenografts. Ann Thorac Surg. 2010;89:1934-41.

5. Klaaborg KE, Egeblad H, Jakobsen CJ, Terp K, Lindskov C, Andersen HR, et al. Transapical transcatheter treatment of a stenosed aortic valve bioprosthesis using the Edwards SAPIEN transcatheter heart valve. Ann Thorac Surg. 2009;87:1943-6.

6. Zegdi R, Achouh P, Berrebi A, Fabiani JN, Blanchard D, Lafont A, et al. Valvein-a-valve implantation: a word of caution. Ann Thorac Surg. 2009;87:348.

7. Rahimtoola SH. The problem of valve prosthesis-patient mismatch. Circulation. 1978;58:20-4.

8. Pibarot P, Dumesnil JG. Prosthesis-patient mismatch: definition, clinical impact, and prevention. Heart. 2006;92:1022-9.

9. Dumesnil JG, Pibarot P. Prosthesis-patient mismatch: an update. Curr Cardiol Rep. 2011;13:250-7.

10. Azadani AN, Jaussaud N, Matthews PB, Ge L, Chuter TA, Tseng EE. Transcatheter aortic valves inadequately relieve stenosis in small degenerated bioprostheses. Interact Cardiovasc Thorac Surg. 2010;11:70-7.

11. Bonow RO, Carabello BA, Chatterjee K, de Leon AC Jr, Faxon DP, Freed MD, et al. 2008 Focused update incorporated into the ACC/AHA 2006 guidelines for the management of patients with valvular heart disease: a report of the American College of Cardiology/American Heart Association Task Force on Practice Guidelines (Writing Committee to Revise the 1998 Guidelines for the Management of Patients With Valvular Heart Disease): endorsed by the Society of Cardiovascular Anesthesiologists, Society for Cardiovascular Angiography and Interventions, and Society of Thoracic Surgeons. Circulation. 2008;118: e523-661.

12. Zoghbi WA, Chambers JB, Dumesnil JG, Foster E, Gottdiener JS, Grayburn PA, et al. Recommendations for evaluation of prosthetic valves with echocardiography and Doppler ultrasound: a report From the American Society of Echocardiography's Guidelines and Standards Committee and the Task Force on Prosthetic Valves, developed in conjunction with the American College of Cardiology Cardiovascular Imaging Committee, Cardiac Imaging Committee of the American Heart Association, the European Association of Echocardiography, a registered branch of the European Society of Cardiology, the Japanese Society of Echocardiography and the Canadian Society of Echocardiography, endorsed by the American College of Cardiology Foundation, American Heart Association, European Association of Echocardiography, a registered branch of the European Society of Cardiology, the Japanese Society of Echocardiography, and Canadian Society of Echocardiography. J Am Soc Echocardiogr. 2009;22: 975-1014; quiz 82-4.

13. Tzikas A, Piazza N, Geleijnse ML, Van Mieghem N, Nuis RJ, Schultz C, et al. Prosthesis-patient mismatch after transcatheter aortic valve implantation with the Medtronic CoreValve system in patients with aortic stenosis. Am J Cardiol. 2010;106:255-60.

14. Blais C, Dumesnil JG, Baillot R, Simard S, Doyle D, Pibarot P. Impact of valve prosthesis-patient mismatch on short-term mortality after aortic valve replacement. Circulation. 2003;108:983-8.

15. Bleiziffer S, Ali A, Hettich IM, Akdere D, Laubender RP, Ruzicka D, et al. Impact of the indexed effective orifice area on mid-term cardiac-related mortality after aortic valve replacement. Heart. 2010;96:865-71.
16. Clavel MA, Webb JG, Pibarot P, Altwegg L, Dumont E, Thompson C, et al. Comparison of the hemodynamic performance of percutaneous and surgical bioprostheses for the treatment of severe aortic stenosis. J Am Coll Cardiol. 2009;53: 1883-91.

17. Cotoni DA, Palac RT, Dacey LJ, O'Rourke DJ. Defining patient-prosthesis mismatch and its effect on survival in patients with impaired ejection fraction. Ann Thorac Surg. 2011;91:692-9.

18. Jamieson WR, Ye J, Higgins J, Cheung A, Fradet GJ, Skarsgard P, et al. Effect of prosthesis-patient mismatch on long-term survival with aortic valve replacement: assessment to 15 years. Ann Thorac Surg. 2010;89:51-9.

19. Mohty D, Dumesnil JG, Echahidi N, Mathieu P, Dagenais F, Voisine P, et al. Impact of prosthesis-patient mismatch on long-term survival after aortic valve replacement: influence of age, obesity, and left ventricular dysfunction. J Am Coll Cardiol. 2009;53:39-47.

20. Azadani AN, Jaussaud N, Matthews PB, Ge L, Guy TS, Chuter TA, et al. Valvein-valve implantation using a novel supravalvular transcatheter aortic valve: proof of concept. Ann Thorac Surg. 2009;88:1864-9.

\section{Discussion}

Dr Mathew Williams (New York, $N Y$ ). This study has a limited number of patients, so it is hard to make any overwhelming conclusions. However, rather than dwell on that, I commend you and the American Association for Thoracic Surgery for deciding to address this issue while this technology is in its infancy. I and several of my colleagues have already changed our surgical strategy in younger patients. We are using tissue valves in much younger patients with almost a planned bailout strategy in the future of performing a transcatheter valve-in-valve rather than a reoperation.

I have 1 comment about the data. I find it is somewhat difficult to try to evaluate the data in terms of looking at EOA, AR grades, and mean gradient as an average for the whole population when the reality is that approximately one third had pure aortic stenosis, one third had pure aortic insufficiency, and one third had mixed. This leads me to my first question. I realize it is entirely anecdotal, but can you comment on any clinical differences, functional differences, in the patients who presented with more aortic stenosis or more insufficiency? It might make sense that in a patient who has severe aortic stenosis it would be worth doing this procedure even if you are going to have some PPM, but perhaps our bar should be a little higher for those with aortic insufficiency.

Dr Seiffert. As you stressed, the limited number of patients in the presented study makes it difficult to distinguish any clinical or functional differences as symptoms or left ventricle dimensions. What I would draw from our data is that the patients may have profited more from a significant reduction of AR rather than a complete relief of stenosis. Therefore, I would imagine that patients with AR due to bioprosthetic degeneration would profit the most from this procedure.

Dr Williams. It would be interesting at some point to see what their left ventricle dimensions were, but, again, it is a small number. Can you provide some guidance given that a lot of us are putting tissue valves in younger patients now? Is there an absolute size that we need to put in patients in whom we are going to try this approach? Perhaps we need to pick their ideal size and add +1 to that, even if it means doing a root enlargement more aggressively in these patients.

Dr Seiffert. We have been discussing this topic thoroughly in our department. As you already stated, patient age is important to that matter. If patients receive a bioprosthesis now, and there 
is a chance they will require a valve replacement because of degeneration in 10 or 15 years, we should plan ahead. Because of the potential problem of PPM, we would rather implant a larger bioprosthesis, even if a root enlargement has to be done to accommodate at least a $23-\mathrm{mm}$ valve. Current studies suggest that root enlargement is not associated with an increase in morbidity and mortality due to the surgical procedure.

We should still keep in mind, as emphasized by Dr Moon in his lecture on PPM, that we do not necessarily see a clinical result or a corollary to the PPM, as determined by echocardiography. Some of these patients may not reach the level of physical activity necessary to experience symptoms or functional changes (eg, in terms of left ventricular mass) due to a persistent stenosis in the light of PPM.

Dr Lucian Lozonschi (Madison, Wis). I congratulate you for an interesting and timely article. It is inevitable now not to tell patients, especially for the past year or so, about the option of valve-in-valve implantation in the future.

I have 2 questions, 1 related to your incidence of paravalvular leak, which we all think should be zero or very small. I haven't seen you report that in the results presented. Were you aware of any rumors of a smaller valve size that can address that issue, or for now shall we stick with putting in larger valves $(>23)$ ?

Dr Seiffert. I agree that paravalvular regurgitation is not a significant problem after valve-in-valve procedures. Apart from 1 patient with a grade 2 paravalvular regurgitation, the remaining patients had no or trivial AR. We follow these patients closely and have not seen any changes in regurgitation or influence on outcome.

To my knowledge, developments of a cuffed transcatheter valve-in-valve prosthesis are under way to avoid any paravalvular leakage. I would imagine this might also reduce the EOA and may therefore not be beneficial with regard to PPM. I do not have any information on smaller THVs being developed for implantation into smaller bioprostheses.

Dr Bansi Koul (Lund, Sweden). Given the small number of patients, did you have an opportunity to see if these patients who had the valves preoperatively, and based on the EOA of those valves already, had some sort of PPM and this is where it became exaggerated in the group?
Dr Seiffert. Are you referring to data before valve-in-valve implantation as opposed to afterward?

Dr Koul. Yes. Do you have some data based on the valves they had in the first instance and from their given BSA that they already had some degree of PPM that became exaggerated after you did a valve-in-valve procedure?

Dr Seiffert. The iEOA did not really significantly change after valve-in-valve implantation. It would have been interesting to retrospectively look at potential PPM immediately after the index procedure 12.5 years ago, for example, echocardiography measurements from back then. Unfortunately, we do not have these data. Because EOA calculations based on the geometric EOA provided by the manufacturer overestimate the actual opening area, we did not perform these calculations.

Dr Christopher Young (London, UK). We have done more than 15 valve-in-valve procedures, and we haven't seen anything like this in our population. We wouldn't expect to see gradients or AR, and yet you showed some deformity when you are actually putting this device into somebody who has a strong circular annulus. Can you explain why you are seeing problems with regurgitation and the deformity, because I wouldn't actually expect that?

How bad are the symptoms in these patients who have a mismatch, how much of it is echocardiographic data, and how much of it is symptomatic if this procedure is done for symptoms in elderly patients?

Dr Seiffert. One patient presented with strong symptoms after valve-in-valve implantation, NYHA class IV, received reoperative valve replacement combined with root enlargement, and has been doing well since then. In the remaining 10 patients, it is difficult to differentiate the symptoms, because these are elderly patients with significant comorbidities, such as pulmonary disease. I agree that a symptom-based approach is appropriate in these elderly patients. Nevertheless, PPM is a potential problem that has to be considered when planning valve-in-valve procedures.

In regard to your first question, we agree that paravalvular AR is not an issue in valve-in-valve procedures. By referring to the pictures from bench ex vivo valve-in-valve implantations, you certainly note an uneven stent expansion after implantation of a 23-mm THV into a 21-mm rigid stent that may result in leaflet distortion and subsequent transvalvular regurgitation. 